\title{
Help-Seeking and Challenges Faced by Transwomen Following Exposure to Gender- Based Violence; A Qualitative Study in the Greater Kampala Metropolitan Area, Uganda
}

\section{Tonny Ssekamatte ( $\nabla$ tssekamatte@musph.ac.ug) \\ Makerere University School of Public Health}

\author{
Aisha Nalugya \\ Makerere University School of Public Health \\ John Bosco Isunju \\ Makerere University School of Public Health \\ Muyanga Naume \\ Transgender Equality

\section{Patience Oputan} \\ Makerere University School of Public Health \\ Juliet Kiguli \\ Makerere University School of Public Health
}

\section{Solomon Tsebeni Wafula}

Makerere University School of Public Health

\section{Simon Peter S. Kibira}

Makerere University School of Public Health

\section{David Ssekamatte}

Uganda Management Institute

\section{Luisa Orza}

Frontline AIDS

\section{Richard K. Mugambe}

Makerere University School of Public Health

\section{Rhoda K. Wanyenze}

Makerere University School of Public Health

\section{Research Article}

Keywords: Transwomen, Gender-based violence, HIV/AIDS, Uganda, Stigma

Posted Date: January 25th, 2022

DOl: https://doi.org/10.21203/rs.3.rs-1244975/v1

License: @ (i) This work is licensed under a Creative Commons Attribution 4.0 International License. Read Full License 


\section{Abstract}

\section{Background}

The prevalence of gender-based violence (GBV) towards transwomen remains high andis both a human rights and public health concern. Nonetheless, there is limited evidence of the referral pathways used by transwomen once exposed to GBV. The current study, therefore, aimed to explore the referral pathways and the challenges faced by transwomen in seeking GBV support services in the Greater Kampala Metropolitan Area, Uganda.

\section{Methods}

A qualitative study design was used. We conducted a total of 20 in-depth interviews, 6 focus group discussions, and 10 key informant interviews. Respondents were recruited using snowball sampling, and purposively selected for interviews. Data were transcribed verbatim and analysed following a thematic framework. NVivo software was used to organise data into themes and subthemes.

\section{Results}

The gender-based violence referral pathways used by transwomen included key population-friendly healthcare facilities, key population-friendly civil society organizations, and friends and family. Key population-friendly healthcare facilities provided medical and psychosocial support services; key population civil society organizations provided shelter, nutritional support, and legal services, whereas friends and family provided emotional support. Lack of recognition of transgender identity; long distances to healthcare facilities; discrimination in some healthcare facilities, civil society organizations, and at the hands of police officers and prison inmates; and the lack of trans-competent healthcare providers and limited scope of GBV services and related equipment made it difficult for transwomen to access GBV support services.

\section{Conclusion}

There were no formal channels for transwomen to access GBV support services. Available avenues such as key population healthcare facilities, key population-friendly civil society organizations, and the police also perpetrated violence against transwomen in the Greater Kampala Metropolitan Area. Our findings suggest the need to formalize referral pathways for transwomen and to sensitize service providers at all points of care about the transgender identity. There is a need to break the structural barriers that limit access to and uptake of GBV support services among transwomen.

\section{Background}

Transwomen are at high risk of gender-based violence (GBV), largely due to the social stigma and marginalization associated with not conforming to culturally accepted gender norms (1-3). Gender-based violence refers to the violence that men and women suffer based on their biological sex, gender identity (e.g., transgender), or behaviours that are inconsistent with societal expectations of "being" a man or woman $(4,5)$.GBV often results from power inequalities based on gender roles (5). GBV can take different forms including emotional, physical, economic, and sexual violence orchestrated by different actors in society and deprives an individual of his/her/their human right to have a life free from violence (6).

Although data on GBV among transwomen remains limited in African settings, global statistics show that GBV among transwomen is prevalent and severe $(3,7,8)$. A review conducted in the United States consisting of 80 data points indicated that $34 \%$ of transwomen suffer from sexual violence, $17 \%$ physical violence and $7 \%$ suffer from psychological or emotional violence (7). In Uganda, GBV is widespread and affects people from different social, economic, and political statuses.

According to Uganda's Demographic and Health Survey (UDHS), approximately 51\% of ciswomen aged between 15 and 49 years have experienced physical violence while $22 \%$ have suffered sexual violence compared to only $8 \%$ of cismen (9). 
Many countries in Africa, including Uganda, have developed strong policy commitments and invested in ciswomen's education and empowerment projects to limit GBV, but the outcomes remain dismal(10).

There is a growing body of evidence linking exposure to GBVto other health risks including the risk of HIV/sexually transmitted infections (STIs), especially through its intermediate risk factors such as substance use, risky sexual behaviours, limited access to healthcare, and lack of access to justice (11). The health risks associated with GBV can be mitigated through improving the help-seeking behaviours of survivors(12). Help-seeking involves a wide range of behaviors such as seeking advice and support from friends and family, obtaining counseling and/or medical care, calling law enforcement in the event of GBV, moving to a violence shelter, pursuing an order of protection, and access to legal services(13). Help-seeking, however, remains a challenge among transwomen, largely due tocombined layers of stigma associated with transgender identity. Transwomen GBV survivors suffer an additional series of challenges when seeking care including financial barriers, discrimination, lack of trans-competence by providers, barriers to health systems, and socioeconomic challenges $(14,15)$. Formal support services for survivors in Uganda are inadequate and do not consider the unique needs of transwomen. There are only $13 \mathrm{GBV}$ shelters that provide survivors with temporary refuge and lodging in Uganda (16), and these are mainly used by ciswomen. These limitations hinder help-seeking among transwomen.

Failure to seek help following exposure to GBV has negative consequences on the health and well-being of transwomen. It is associated with poor multiple poor health outcomes including HIV infections, mental distress, and premature mortality(5). Despite these consequences, care and help-seeking and the challenges faced by transwomen following exposure to GBV is not understood $(17,18)$, especially in transphobic societies like Uganda. Yet, care and help-seeking following GBV is very important for access to emergency services such as medical care, including access to post-exposure prophylaxis for HIV, psychosocial support and access to legal services. This study therefore sought to document the help-seeking and challenges faced by transwomen when seeking related services in the Greater Kampala Metropolitan Area, Uganda.

\section{Materials And Methods Study design and area}

A cross-sectional study design using qualitative data collection methods was conducted. The study was carried out in the Greater KampalaMetropolitan Area (GKMA) that consists of Kampala city and the neighboring districts of Wakiso, Mukono, Mpigi, Buikwe, and Luweero. It has a rapidly growing population that, in 2019,the Uganda Bureau of Statistics estimated at $6,709,900$ people in an area of $8,451.9 \mathrm{~km} 2$ (3,263.3 square miles). It is the major business and industrial hub of Uganda and contributes over $70 \%$ of the country's industrial production and over 60 percent of the country's GDP. Kampala is home to the majority of civil society organizations(CSOs) and keypopulation-friendly healthcare facilitiesthat serve key populations in Uganda, including transwomen.

\section{Study population}

The study population includedtranswomen residing in GKMA. The study included 60 transwomen aged 18 and above. Other study participants included key informants (KIs) such as senior staff of civil society organizations working with transwomen, representatives of organizations providing access to justice services, trans-friendly sexual and reproductive health (SRH) service providers, and policymakers.

\section{Sample size, sampling procedure, and data collection techniques}

The snowball sampling technique was used in the recruitment oftranswomen for the in-depth interviews (IDIs) and focus group discussions (FGDs). CSOs guided the identification of primary seeds for IDIs. The research assistants interviewed the 
selected seeds and oriented them on how to recruit secondary seeds that fit our criteria. These were interviewed after providing written informed consent. A total of 20 IDIs, 6 FGDs, and $10 \mathrm{KIs}$ were used to obtain data from the purposively selected respondents in the GKMA. This was informed by the level of theoretical saturation (19). We purposively interviewed $\mathrm{KI}$ based on their positions and presumed understanding of GBV and referral pathways among transwomen. $\mathrm{KI}, \mathrm{FGD}$, and IDI guides were used to elicit data on the referral pathways of survivors of GBV and their experiences while seeking postGBV support.

\section{Data management and analysis}

Audio files were transcribed verbatim by three experienced transcribers. Interviews conducted in the local dialect were also transcribed and translated without losing meaning by qualified personnel. Transcripts were read several times by two members of the study team, who then developed codes and codebook definitions based on the study objectives while integrating emerging themes from the data. The codebook was discussed and agreed upon by all members of the core study team. Coding of the transcripts was done using ATLAS.ti software to make analysis easier. The code reports generated by ATLAS.ti were read and discussed by study investigators who afterward agreed on themes, organising themes, and basic codes. A socio-ecological model was used in the presentation of findings.

\section{Quality control and assurance}

We recruited competent research assistants with experience of working with key populations. These were trained before data collection on the study protocol, ethics, and transwomenterminologies. Research assistants were closely supervised during data collection to ensure that they followed the study protocol and research ethics.

\section{Results}

\section{Background characteristics of the participants}

Of the 60 participants, 33 resided in Mukono district, 56 were aged 18-28 years, 38 had attained secondary education, 55 were single and 18 were Catholic. Thirty-one of the participants engaged in sex work for a living (Table 1).

\section{Table 1: Background characteristics of the study participants}




\begin{tabular}{|c|c|c|}
\hline Variable & Category & Number of respondents \\
\hline \multirow[t]{3}{*}{ District of residence } & Mukono & 33 \\
\hline & Kampala & 21 \\
\hline & Wakiso & 6 \\
\hline \multirow[t]{2}{*}{ Age } & $18-28$ years & 56 \\
\hline & 29-39 years & 4 \\
\hline \multirow[t]{4}{*}{ Education level } & No formal education & 1 \\
\hline & Primary & 10 \\
\hline & Secondary & 38 \\
\hline & Tertiary & 11 \\
\hline \multirow[t]{2}{*}{ Marital Status } & Single/never married & 55 \\
\hline & Married & 5 \\
\hline \multirow[t]{6}{*}{ Religion } & Catholic & 18 \\
\hline & Protestant & 14 \\
\hline & Muslim & 20 \\
\hline & Pentecostal & 5 \\
\hline & Seventh-day Adventist & 2 \\
\hline & Other & 1 \\
\hline \multirow[t]{4}{*}{ Main source of income } & Sex work & 31 \\
\hline & Salaried & 9 \\
\hline & Casual work & 7 \\
\hline & Other businesses & 13 \\
\hline \multirow[t]{4}{*}{ Type of sex work } & Street-based & 2 \\
\hline & Entertainment place-based & 7 \\
\hline & Residence/home-based & 21 \\
\hline & Other & 6 \\
\hline \multirow[t]{4}{*}{ Living arrangements } & Home with family & 14 \\
\hline & Home without family members & 21 \\
\hline & Fellow transwomen & 14 \\
\hline & No home to stayat & 11 \\
\hline
\end{tabular}




\begin{tabular}{|lll|}
\hline Theme & Subthemes & Codes \\
Help-seeking & Sources of support & $\begin{array}{l}\text { Support from key population-friendly } \\
\text { healthcare facilities for medical services }\end{array}$ \\
& $\begin{array}{l}\text { Seek GBV support from key population-friendly } \\
\text { civil society organizations }\end{array}$
\end{tabular}

A minority of GBV survivors report to police

Seek support from friends and family

Nowhere to report incidences of GBV

Challenges while help-seeking at healthcare facilities

Challenges experienced during help-seeking challenges
Health system-related

Long distances to healthcare facilities providing GBV support services

Gender-based violence in some healthcare facilities

Lack of trans-competent healthcare providers

Limited GBV services and equipment available

Internalized stigma among transwomen

Challenges experienced at civil society organizations

Legal system-related challenges
Exposure to GBV by some managers of some civil society organizations

Discrimination of transwomen by some staff at civil society organizations

Lack of trans-competent legal personnel in civil society organizations

Lack of recognition of transwomen identity by the existing laws

Being asked inappropriate questions about experiences of GBV and gender identity 


\section{Violence perpetrated by police officers and prison inmates}

\section{Help-seeking following exposure to GBV}

Respondents mentioned that they sought GBV support from civil society organizations, healthcare facilities, key populationfriendly healthcare facilities, peer educators, and at times family and friends. It was reported that the respondents rarely sought GBV support from the police. The GBV support referral pathways are elaborated in the following subsections.

\section{Support from key population-friendly healthcare facilities for medical services}

Respondents who experienced GBV reported that they sought support from key population-friendly healthcare facilities and, on rare occasions, public healthcare facilities with key population programs. Theyoften sought post-exposure prophylaxis (PEP) for HIV, HIV testing and counselling services, and treatment for injuries sustained during the violence.

"Some guy forced me into sex and I got torn. I started bleeding so much and I called my friend for advice. He told me to go to the hospital and explain to the healthcare providers. That is how I first went to facility XXXX. They first gave me an injection and some tablets to reduce pain and afterward I went home."(IDI)

"Besides the healthcare facility, I can't run anywhere else. Even at the police station, I can't go there. After going to the facility, I return home and I stay there with my problems until I get better."(IDI)

\section{GBV support from key population-friendly civil society organizations}

Respondents mentioned that they sought GBV support from key population-friendly civil society organizations. Support received was in form of psychosocial support, e.g., counselling, legal support such as mediation with intimate partners, relocation, shelter, and nutrition support. When asked where they seek GBV support services, one of the respondents said:

"When the community where I was living found out I was a transwoman, they beat me up and I ran to PP [key population advocacy civil society organization]. What PP did was to carry out an investigation and when they found out it was true, they relocated me to a safer place." (IDI)

"There are some transwomen who have been evicted from their homes because of transphobia. So, QQ [LGBT organization] provides shelter and feeding to such survivors." (FGD)

"Yes, organizations like YY give us some GBV support. I stole someone's husband and I was burnt and badly beaten, but I got full treatment under their support." (FGD)

"And then there is ZZZ and AAA [key population-friendly civil society organization]. These have got clinics which can provide healthcare services to transwomen when they experience violence." (FGD)

"There are other organizations that have worked hard to save transwomen. Many transwomen report violence such as cases of slapping and beating to these organizations. The executive director of QQ [LGBT organization] together with the one of $P P$ [key population advocacy civil society organization] always help out transwomen because they are paralegals." (FGD) 
"We don't report to police because QQ [LGBT organization] has helped us gain justice as transgender people. They work on us and ensure that we get the support needed. Even if at times, justice takes long to be realized."(FGD)

\section{A minority of GBV survivors reports to the police}

Only a few of the respondents ever reported instances of GBV to the police. One of the key informants estimated that less than $5 \%$ of transwomendid sobecause the police also perpetrated violence which consequently led to stigmatization of transwomen. In addition, respondents also pointed out that they feared reporting cases of GBV to police since they did not believe that transwomen's gender identity existed.

"It is very hard. I think less than $5 \%$ of the cases are reported to police because it also stigmatizes transwomen." (KI)

"For police, you can never [report to them]! I have never seen someone courageous enough to go to the police to report the partner or report anyone who has beaten her. Even though it's a landlord who has beaten a transwoman, she cannot go and report to the police. Usually, the pathway is 'see the counsellor and then the doctor for medical treatment such as PEP in case you need to.' But if you mention the word police, they will just say 'let's leave it!'(KI)

"I can't go to the police. They are still in denial that transgender people exist. They say you are a man; how did you get raped!" (IDI)

Out of all the interviews, only one respondent acknowledged that she reported to the police. The respondent mentioned that the attitude of police officers was now changing compared to the past, and that they concentrate on the cases rather than gender identity.

"Police is now better. Before you would go to the police and the police officers would insult you saying:'Iook at this gay fool.' But nowadays, if you go to the police, they overlook your gender identity and consider the case that has taken you there."

(IDI)

\section{Seeking support from friends and family}

A minority of the respondents mentioned that they sought support from friends and family in the event of exposure to GBV, particularly in healthcare settings. The survivors often confided in friends, especially transwomen. In addition, some friends helped the survivors to access medication in case they were afraid to go to the healthcare facilities.

"If such a thing [violence] happens, you may run to your friend who is confident and not scared of going to these facilities. She can collect for you the medication if she doesn't fear."(FGD)

"I have friends who are also transwomen, so I confide in them. I prefer friends from the trans community because they share the same experience so that makes you more comfortable than speaking to another person."(IDI)

Whereas a considerable number of respondents sought GBV support from their friends, some felt that some friends would breach confidentiality and spill their secrets.

"If I need counseling, I have my brothers and sisters-in-law that support me. It's better than going to your friend and they spill your secrets." (FGD)

\section{Nowhere to report incidences of GBV}


A considerable proportion of the respondents opted not to report GBV experiences since they were not aware of where to go and because their gender identity was not recognized by law.

"Some of our employers will use all possible ways to entice you into having sex with them. When you refuse, they rape you before you're out of the office! At times, you don't want to have sex, but you have nowhere to report such a case." (FGD)

"The law doesn't favour us [transwomen], so we are not recognized. Police officers take advantage of this and mistreat us. We don't have anywhere to report them." (FGD)

"I go through all that alone. I have experienced a lot! I started managing alone since my dad disowned me. At some point, I got infected with HIV. The people that infected me are still there and I am here surviving." (IDI)

Challenges faced while seeking GBV support services from the healthcare facility

\section{Challenges while help-seeking at healthcare facilities}

Whereas healthcare facilities were a haven to some transwomen post-GBV, some study participants reported challenges such as limited health services and equipment, long distances to the facility, abuse from healthcare workers, and gaps in the follow-up of the GBV cases.

\section{Long distances to healthcare facilities providing GBV support services}

Respondents mentioned that healthcare facilities providing key population-friendly services, including GBV support, were located far away from where they lived. They added that due to the long distances to such healthcare facilities and lack of money, it was very difficult for them to travel just after experiencing violence or while sick. The challenge of longdistance was exacerbated by a lack of equipment such as the proctology machine in nearby healthcare facilities, which forced many transwomen to travel to the only healthcare facility with such equipment.

"We would get the treatment but at times the healthcare facility is located far away. For someone that is already very sick, can't even walk, and has not been working, travel to the healthcare facility may become difficult." (FGD)

"We have mentioned all those transgender-friendly health facilities but the distance also hinders us from getting GBV services. For instance, only KK [key population-friendly healthcare facility] has the proctology machine. Therefore, if you require such services you have to go to KK. So, we request that they put these machines in other hospitals to reduce travel and related costs." (FGD)

\section{Gender-based violence in some healthcare facilities}

Respondents reported that the violence they experienced at the hands of healthcare providers while seeking GBV support services discouraged them from visiting healthcare facilities. Specifically, they mentioned inappropriate questions about their gender identity, denial of medical services due to their gender identity, and discrimination as some of the main challenges they faced while seeking GBV support services. Respondents mentioned that some healthcare providers went on to call the police to get them arrested or media representatives to create a news story.

"We would go to those healthcare facilities but we are asked a lot of questions. For instance, we are asked questions like 'what happened to your anus?' Then they will tell us to lay on the bed for a check-up and by the time you realize, you're surrounded by police or media personnel." (FGD) 
Concerning asking inappropriate questions about GBV experience and transwomen's identity, respondents revealed that some healthcare providers asked where and why they had been raped, and how a fellow man can beat them up. To transwomen, such questions were demeaning and traumatizing. This consequently hindered access to and use of available GBV support services in such healthcare facilities.

"When I was raped, at first I didn't tell anyone. I was in pain and hurt that I had no one to tell. I felt like killing myself. I used to sit on my bed and shed tears. Until I got someone that I shared my problem with and he took me to the hospital for a checkup. Because of what the doctor took me through, I reached a moment and told them that we should just leave the treatment. The doctor was telling me that, "they can't rape you! How can they rape you? You also went there when you wanted it[sexual intercourse]." I told the person I came with that we should go." (IDI)

"I have seen some transwomen who have been affected. She is raped, not even raped by one person but gang-raped, and by gang-raped I mean three men and above. You get it. It happens to them. Is she going to go to the hospital? Okay, she is going to go there, and then she is asked 'where' she was raped. That question is very rude and demeaning. Do you know what it means? You are raped and when you go to report the case, they ask you 'where were you raped?"'(IDI)

"Usually when you go to access a service such as counselling, HIV testing or consulting and you are telling the story that" was with my boyfriend and we ended up fighting.' The healthcare provider will ask you 'how can a fellow man beat you? That's so weird."'(KI)

Respondents revealed that they were at times denied medication once the healthcare providers found out their identity, which made it difficult for them to express themselves while seeking GBV support services.

"They discriminate against us after knowing who we are. Some can't even give you medication. Because of this, we fear to express ourselves to them. A health worker might know the cause of let's say bruises in the anus, and they can refuse to give us help." (FGD)

\section{Lack of trans-competent healthcare providers}

Some survivors of GBV encounteredtrans-incompetent healthcare providers. Some healthcare providers in healthcare facilities used by transwomen were not aware of the transgender identity.

"There is also ignorance about transgender people. When you talk about transwomen, you have to first explain yourself so much. When you talk about GBV, there is no particular service offered or particular point available to take care of transwomen." (IDI)

\section{Limited GBV services and equipment available}

Besides the lack of competent healthcare providers, respondents also mentioned that healthcare facilities lacked medicines and equipment. As a result, GBV survivors were requested to buy such medicines, yet they lacked money. Some respondents mentioned that whereas some healthcare facilities provided GBV services, gaps remained in the follow-up of such GBV cases.

"In most cases, most of the medications and equipment are not available at the healthcare facilities. They prescribe medication and if you have the money, you go and buy. Yet, in most cases, when you decide to go to these healthcare facilities you don't have money. So, you just stay without treatment." (FGD)

"The current referral system is not strong. I have sometimes referred transwomen for drugs but they are out of stock or they are not there in the pharmacy." (KI) 


\section{Internalized stigma among transwomen}

Internalized stigma evidenced by feeling embarrassed to share GBV experiences with healthcare providers hindered transwomen's access to GBV support services. Some transwomen feared to be seen by their friends while accessing GBV services from known transgender-friendly healthcare facilities. Respondents also mentioned that they found it difficult to confide in healthcare providers because they believed that they didn't understand them since they are not like them.

"As a transwoman, you may have a challenge explaining GBV experiences to healthcare providers. If your partner raped you and you have bruises around your anus, explaining what happened to the health worker is challenging and embarrassing, especially to people who don't understand us." (FGD)

"The reason why some of us get infections is that we fear to go to these healthcare facilities [key population healthcare facilities] since they know us. And once they know you, it might be the beginning point of discrimination." (FGD)

\section{Challenges experienced by transwomen while help-seeking at civil society organizations}

\section{Exposure to GBV by some managers of some civil society organizations}

Respondents mentioned that the managers of some non-governmental organizations (NGOs) were also perpetrators of GBV. The transwomen were at times subjected to sexual and emotional violence which in the end discouraged them from seeking GBV support services such as obtaining shelter.

"Some of the managers of some NGOs are perpetrators of GBV. I decided to come to this NGO and stay. However, I am tortured but I keep quiet. Sometimes he can say 'if you want to stay here, you must first have sex with me.' If you refuse, he starts insulting and abusing you and he tells you to leave his shelter. You end up homeless with no one to support you. He doesn't give me much help but he says hurtful words." (IDI)

"Sometimes you may be hungry but you fear asking the executive director for food because you fear to be harassed and chased out of the shelter. I was in a happy family but the conditions were not good and I left. Sometimes he harasses me telling me I am a failure but I just keep quiet and patiently look for money to get capital and start working again." (IDI)

\section{Discrimination of transwomen by some staff at civil society organizations}

Some respondents experienced discrimination by some civil society organizations. Preference was often given to men who have sex with men (MSM) as opposed to transwomen.

"Some organizations startup to help transwomen and they get funding. However, when we go to these organizations, they discriminate against trans persons and instead attend to MSM."(FGD)

"Most of these NGOs help their friends, they used to help us in the past but now that we are many, they select whom to help." (IDI)

\section{Lack of trans-competent legal personnel in civil society organizations}


Respondents mentioned that there was a lack of trans-competent legal personnel in civil society organizations and that the available legal personnel did not understand their experiences as transwomen.

"Most legal personnel are straight. They wouldn't understand us. And they are not in these events or actions with transwomen so they can't know better." (IDI)

\section{Challenges faced while seeking GBV support services from law enforcement settings}

\section{Lack of recognition of trans identity by existing laws}

Respondents mentioned that transwomen were not recognized by existing laws and law enforcers such as the police. This meant that they could not express their gender identity while seeking GBV-related services.

"The law doesn't recognize transwomen, and police officers are law implementers. You can't tell them that you are trans yet the trans are not recognized by the law." (FGD)

The fact that transwomen were not recognized by the law meant that they often ended up being imprisoned while they sought GBV support services from the police. At times, police officers were also perpetrators of GBV. These challenges are highlighted in the following quotes:

"Police officers are also perpetrators of GBV. As I said, you might be attacked in the bar and you go to report. When you reach there [the police] and they ask you 'why did they beat you?', if you tell the police who you are [transwoman], it might fuel the police officer to put you behind bars." (FGD)

"I was arrested by police but I could neither express myself as a woman nor as a man. I was scared of expressing who I am. Sometimes they arrest you for another case and they end up charging you for being a transwoman." (IDI)

\section{Being asked inappropriate questions about GBV and gender identity}

Respondents mentioned that they were asked inappropriate questions about their GBV experience and their gender identity whenever they reported a case to the police. Police officers at times asked whether they are female or male, how they got raped, and why they went to a man's place of residence. Transwomen felt embarrassed to tell the police officers that they had sexual intercourse with a man. Consequently, this affected their access to GBV services. This is highlighted in the following quote:

"When you go to the police to report a case of rape, they will ask you:'are you male or female? How were you raped? Why did you go to see the guy in the first place? What were you going to do there?' How will you tell them that he is your boyfriend and you were going to have sex with him? Will you say it? Of course not! She [transwoman] will stay home, use warm water, salt and painkillers. Maybe she would go for the [HIV] testing after she is better and there are no more bruises. When she is asked how she got infected she wouldn't be able to tell them. How do you even open up that 'I was raped by five men yet I am a man and I also have a dick." That's what the society expects you to be, a man, which you aren't." (IDI)

\section{Violence perpetrated by police officers and prison inmates}

Respondents mentioned that they did not have confidence in the police since, at times, this exposed them to more violence. Some respondents mentioned that they have been raped by inmates while in prison cells. In addition, some respondents 
mentioned that, at times, they had been forced to have unprotected sexual intercourse with police officers with the promise of being released from custody. Some respondents who experienced violence in prisons feared to report it due to being ashamed of their experience.

"Some police officers will force you to have sex with them against your will. Some say that "I first want to have sex with you and have a feel of how it is before I release you'. They use you without lubricants or a condom and even after sexually abusing you, they end up not releasing you even when you need to test for HIV. You can't report the abuse anywhere and you don't even know their HIV status." (IDI)

"Our fellow prisoners rape us. Remember, when the police officer takes you to prison, they will tell everyone 'that one is gay.'The prisoners start to applaud the police officer saying 'ok, bring him in'. They forcefully have sex with you and at times you end up getting injuries. You end up rotting from there and with no treatment in the prison cells. Sometimes, you can't even explain it to the nurses in the prison because they start judging you."(IDI)

"When police arrest you, they first call news reporters, parade you, and accuse you of cross-dressing. By morning you are all over the news and that is why we never go to the police. I hate them!" (IDI)

It was also reported that access to GBV services offered by police was hindered by the corrupt tendencies of police officers. The respondents mentioned that they often ask them for bribes if they wanted to be helped.

"Our main referral place is police especially for cases of fighting and physical violence. However, at the police, they often want kickbacks. Sometimes these police people need bribes, yet sometimes the survivors have no money. In the end, the legal services provided to them [the survivors] are not efficient because of the barriers." (KI)

\section{Discussion}

This study sought to document help-seeking and the challenges faced by transwomen when seeking related services in the Greater Kampala MetropolitanArea, Uganda.Transwomensought help fromkey population-friendly healthcare facilities, key population-friendly civil society organizations, friends and family, and police in rare cases. The challenges faced by transwomen while seeking GBV-related servicesincluded long distances to healthcare facilities;lack of trans-competent healthcare providers and equipment to extend appropriate services to transwomen; GBV experiences at some civil society organizations; discrimination by some staff at CSOs; and lack of trans-competent legal personnel GBV services.

Our study revealed that transwomensought help from key population-friendly healthcare facilities for healthcare services such as PEP in the event of exposure to GBV. The majority of transwomen sought PEP from key population healthcare facilities aftersexualviolence like rape. They also sought treatment for wounds in case of physical violence, and psychosocial support - for example,counseling - once subjected to emotional and mental abuse.Transwomen often opt for key population-friendly healthcare facilities since, at times, they havetrans-competent healthcare providers(20)who are more likely to respect their gender identity and confidentiality compared to general healthcare facilities. Such healthcare facilities also have gender-affirming medical services and equipment such as proctoscopes(21), used in examining the rectum, which is not the case in general healthcare facilities. Visiting key population-friendly healthcare facilities makes it easier for transwomen to access other HIV prevention and care services such as condoms, lubricants, and screening for sexually transmitted infections since these healthcare facilities receive and treat them with less discrimination,compared to general healthcare facilities.

Key population-friendly civil society organizations were seen as a haven for access to GBV services among transwomen.Such organizationscreate trusted and safe platforms for the provision of psychosocial services such as counseling and legal support. CSOs engage in protectingthe human rights of marginalized persons and most atriskpopulations such as transwomen through enhanced access to justice, research and advocacy, and legal and human rights awareness. They also have community paralegals who help mediatewith intimate partners involved in gender-based 
violence, while others have been at the forefront of the HIV response with special emphasis on key populations (22). Some CSOs provide nutritional support and GBV shelters to survivors. GBV shelters are part of the referral pathways and are used to support the provision of temporary refuge, lodging, and other services, and to link survivors to medical, legal, economic, and psychosocial services (22-26). Transwomen therefore opt to turn to key population-friendly civil society organizations to access related services along the referral pathway.

Our study revealed that some transwomen turned to friends and some family members for psychosocial support once exposed to sexual, physical, and emotional violence. Friends and family were a source of emotional support and reminded survivors to adhere to treatment. Some friends and family members often picked up medication for some GBV survivors. The role of friends and family in increasing access to GBV support services is widely documented $(3,27)$. There is evidence of family members protecting transwomen against further victimization from formal resources such as the police(3). Our findings are consistent with those reported byNemoto, Bödeker (28) among the transgender population in San Francisco and Oakland, United States.Nemoto, Bödeker (28)reported that some GBV survivors received support from family members and friends.

This study revealed that a minority of GBV survivors reported to the police. The Ugandan police force, through the Department of Child and Family Protection, has the mandate to provide psychosocial support and telephone counseling services to GBV survivors; to link clients in need of care and protection to services or service providers; to follow up reported cases with the area police commanders; and to raise awareness on human rights with the public. A few transwomen in the current study may therefore have opted to seek such services from law enforcement officials, particularly when physical violence erupted. The fact that only a few transwomen sought GBV-related services from the police highlights the disconnect between the transcommunity and the police, which can be attributed to fear of persecution among transwomen since same-sex intercourse is not legal in Uganda. In addition, many police officers are not aware of transgender identity. Our study also revealed that transwomendid not seek help from the police due to fear of being asked inappropriate questions about their gender identity, and gender-based violence such as rape at the hands of police officers and other inmates. Similar findings have been reported among transwomen in Latin America and the Caribbean (29), Australia (30), Uganda $(31,32)$, Kenya $(33)$ and South Africa $(34,35)$. Our findings therefore highlight the need to train law enforcers on transgender identity to increase the uptake of GBV-related services.

The current study revealed that some GBV survivors had nowhere to report such cases. This could be attributed to human rights violations such as the criminalization of transgender identity and same-sex intercourse, religious and cultural beliefs, stigma and discrimination, andviolence, as highlighted in Uganda's penal code(36). In addition, transwomen do not trust CSOs and law enforcement bodies like the policesince they arealso perpetrators of GBV. Whereas CSOs and police play an important role in linking GBV survivors to psychosocial support services such as counseling, temporary refuge, and healthcare, managers of some civil society organizations and police officers were reported to be perpetrators of GBV.Failure to report GBV experiences may also have resulted from the fact that the current existing referral pathway does not take into consideration the unique needs of transwomen. The referral pathway is mainly known and used by cisgender people(5). The cultural beliefs that portray men as strong and powerful enough to defend themselves during GBV exposure may also limit transwomen'suse of the current referral pathways. There is evidence of minimal recognition of transwomen and acknowledgment of their increased risk for HIV infection (37), which can partly explain the non-existence of a GBV referral pathway.

Transwomen in the current study faced the challenge of long distances to key population healthcare facilities while seeking GBV support services such as PEP, HIV testing, and counseling services. Long distances to such facilities led to delayed access to appropriate treatment, and increased loss to follow-up if a victim was exposed to HIV. The fact that key population-friendly healthcare facilities were located far away from the residences of transwomen increased the cost of accessing GBV-related services. Many transwomen in Uganda are unemployed and live in absolute poverty. Long distances to healthcare facilities have previously been shown to impede the take-up of healthcare services among transwomen (38).

Page 14/19 
Lack of trans-competent healthcare providers in both key population and general healthcare facilities hindered transwomen from accessing GBV-related services. There is evidence of transwomen being prone to disrespect, blackmail, labeling, breach of confidentiality, discrimination, and stigma at the hands of healthcare providers, which hinders access to GBV services at healthcare facilities. The role of competent healthcare providers in improving access to health services is widely documented $(29,39-41)$. Training healthcare providers on transgender health is therefore critical in addressing the disparity in GBV-related services that transwomen in Uganda experience.

The limited scope of GBV services and lack of equipment used for examination of transwomen hindered access to and use of GBV services. Transwomen suffer from unique injuries and sexually transmitted infections such as inflammation of the rectum, which requires equipment that may not be common in general healthcare facilities, since such conditions are rare in the general population. To the best of our knowledge, only two healthcare facilities (one in the GKMA and the other in western Uganda) currently provide proctology services. This implies that transwomen have a limited choice in terms of access to such services. The limited access to healthcare facilities with the required equipment for examination and treatment of injuries or infections arising from exposure to GBV means that transwomen may find it difficult to access particular treatment and care services when in need. Delayed access to appropriate treatment and care services among transwomen may result in the development of multi-drug resistantpathogens which are more complex to treat (38).

This study revealed that discrimination of transwomen by some CSO staff is a hindrance to access to GBV services. Whereas CSOs are funded to extend services such as HIV testing, lubricants, nutritional support, and legal protection to transwomen, there was an inequality in the provision of such services to transwomen. CSOs favored MSM at the expense of transwomen. Discrimination by CSO staff may have resulted from transphobia, which is often driven by the physical appearance and behavioral dynamics of transwomen(5). Unlike MSM, transwomen often behave like ciswomen in terms of their dress code, use of accessories,jewellery, and makeup. This may at times not be considered acceptable to other genders, especially cisgender, thus fueling discrimination(38). This may have been made worse by the lack of transcompetent legal personnel in CSOs.

\section{Strengths and limitations}

To the best of our knowledge, this is the first study to document help-seeking and challenges faced by transwomen in the process of accessing GBV-related services. The study used d a qualitative approach that can enable researchers, policymakers, and implementers to obtain a deeper understanding of GBV among transwomen in transphobic communities. Nonetheless, our study had a few limitations. Experience of GBV is often stigmatizing which may have limited some respondents from fully opening up to the research team. However, we trained the research assistants on qualitative skills such as probing to obtain detailed information on the various themes.

\section{Conclusions}

Whereas there was no formal GBV referral pathway, transwomen in the current study used key population-friendly healthcare facilities for medical and psychosocial support, key population-friendly civil society organizations for shelter and legal support, and friends for emotional support. Only a few of the respondents mentioned approaching the police for GBV support, which was attributed to fear of being asked inappropriate questions about their gender identity, not being recognized by the law, and violence perpetrated by police officers and prison inmates. Some transwomen were not aware of anywhere to report in the event of exposure to GBV. Lack of recognition of transgender identity; long distances to healthcare facilities;exposure to GBV evidenced by discrimination in some healthcare facilities, civil society organizations, and at the hands of police officers and prison inmates; and the lack of trans-competent healthcare providers and limited scope of GBV services and related equipment made it difficult for transwomen to access GBV support services. Our findings suggest the need to prioritize programs and interventions aimed at reducing GBV towardstranswomen and adapting the existing referral pathways to cater to the unique needs of transwomen.

Page 15/19 


\section{Abbreviations}

GBV: Gender-based Violence

GKMA: Greater Kampala Metropolitan Area

HIV: Human Immunodeficiency Virus

CSOs: Civil Society Organizations

STIs: Sexually Transmitted Infections

\section{Declarations}

\section{Ethics approval and consent to participate}

Ethical clearance was obtained from The AIDS Support Organization (TASO) Research and Ethics Committee (TASOREC/052/2020-UG-REC-009). The study was also registered with the Uganda National Council of Science and Technology (UNCST) under registration number SS557ES. Written informed consent was obtained from study participants before all interviews. A thorough explanation of the objectives, benefits, and risks of the study was carried out by the research assistants before conducting the interviews. All information obtained during the study was treated with confidentiality, identifiers were used to mask the identity of study participants, and data access was restricted to the core research team. Participation in the study was entirely voluntary and informed written consent was obtained. Individual privacy was ensured by treating the data as confidential and conducting the interviews from secluded places. Data were not collected on the names, place of residence or any other information that would reveal the identity of respondents. This reduced the risk of respondents being recognized by law enforcers like the police.

\section{Consent for publication}

Not applicable

\section{Availability of data and materials}

The transcripts analysed during the current study are available from the corresponding author upon reasonable request.

\section{Competing interests}

The authors declare that they have no competing interests.

\section{Funding}

This study was funded by ACCESS consortium through Frontline AIDS. However, the funders did not play any role in the conceptualization and drafting of the manuscript.

\section{Authors' contributions}

TS, MN, AN, RKW and LO conceptualised the study, participated in data collection, analysis and drafted the manuscript. JBI, PO, JK, STW, SPSK, DS andRKMparticipated in the analysis, and drafting of the manuscript. All authors read and approved 
this manuscript before submission to this journal.

\section{Acknowledgements}

We would like to thank the study participants for sparing their time to participate in the study. Special thanks also go to the research assistants for their invaluable effort in the design and execution of data collection. We are grateful for the support provided by Transgender Equality Uganda during the design and implementation of the study.

\section{References}

1. Inter-Agency Standing Committee. Guidelines for integrating gender-based violence interventions in humanitarian action: Reducing risk, promoting resilience and aiding recovery. Inter-Agency Standing Committee; 2015.

2. Budhwani H, Turan B, Hasbun J, Rosario S, Tillotson L, McGlaughlin E, et al. Association between violence exposure and condom non-use among transgender sex workers in the Dominican Republic: the mediating role of trust. International journal of STD \& AIDS. 2017;28(6):608-12.

3. Sherman ADF, Allgood S, Alexander KA, Klepper M, Balthazar MS, Hill M, et al. Transgender and Gender Diverse Community Connection, Help-Seeking, and Mental Health Among Black Transgender Women Who Have Survived Violence: A Mixed-Methods Analysis. Violence Against Women. 2021;0(0):10778012211013892.

4. Evens E, Lanham M, Santi K, Cooke J, Ridgeway K, Morales G, et al. Experiences of gender-based violence among female sex workers, men who have sex with men, and transgender women in Latin America and the Caribbean: a qualitative study to inform HIV programming. BMC International Health and Human Rights. 2019;19(1):9.

5. Wirtz AL, Poteat TC, Malik M, Glass N. Gender-Based Violence Against Transgender People in the United States: A Call for Research and Programming. Trauma, Violence, \& Abuse. 2020;21(2):227-41.

6. UN Women. Ending violence against women and girls: Programming essentials. Geneva: United Nations Women; 2013.

7. Reisner SL, Poteat T, Keatley J, Cabral M, Mothopeng T, Dunham E, et al. Global health burden and needs of transgender populations: a review. The Lancet. 2016;388(10042):412-36.

8. Brennan J, Kuhns LM, Johnson AK, Belzer M, Wilson EC, Garofalo R, et al. Syndemic theory and HIV-related risk among young transgender women: the role of multiple, co-occurring health problems and social marginalization. American journal of public health. 2012;102(9):1751-7.

9. UBOSa. Uganda Demographic and Health survey (UDHS). Uganda Bureau of Statistics report 2016 [Available from: http://www.ubos.org/onlinefiles/uploads/ubos/pdf\%20documents/Uganda_DHS_2016_KIR.pdf.

10. Cools S, Kotsadam A. Resources and intimate partner violence in Sub-Saharan Africa. World Development. 2017;95:211-30.

11. Lombardi EL, Wilchins RA, Priesing D, Malouf D. Gender violence: Transgender experiences with violence and discrimination. Journal of homosexuality. 2002;42(1):89-101.

12. Howell J, Maguire R. Seeking help when transgender: Exploring the difference in mental and physical health seeking behaviors between transgender and cisgender individuals in Ireland. Int J Transgend. 2019;20(4):421-33.

13. Gover AR, Tomsich EA, Richards TN. Victimization and help-seeking among survivors of intimate partner violence. 2015.

14. Safer JD, Coleman E, Feldman J, Garofalo R, Hembree W, Radix A, et al. Barriers to healthcare for transgender individuals. Curr Opin Endocrinol Diabetes Obes. 2016;23(2):168-71.

15. Leddy AM, Weiss E, Yam E, Pulerwitz J. Gender-based violence and engagement in biomedical HIV prevention, care and treatment: a scoping review. BMC Public Health. 2019;19(1):897.

16. UN Women. GBV shelters Uganda: Global Database on Violence against Women Kampala2016 [Available from: https://evaw-global-database.unwomen.org/fr/countries/africa/uganda/na/gbv-shelters. 
17. Donovan C, Barnes R. Help-seeking among lesbian, gay, bisexual and/or transgender victims/survivors of domestic violence and abuse: The impacts of cisgendered heteronormativity and invisibility. Journal of Sociology. 2020;56(4):554-70.

18. Calton JM, Cattaneo LB, Gebhard KT. Barriers to help seeking for lesbian, gay, bisexual, transgender, and queer survivors of intimate partner violence. Trauma, violence, \& abuse. 2016;17(5):585-600.

19. Saunders B, Sim J, Kingstone T, Baker S, Waterfield J, Bartlam B, et al. Saturation in qualitative research: exploring its conceptualization and operationalization. Quality \& Quantity. 2018;52(4):1893-907.

20. Mmbaga EJ, Leyna GH, Leshabari MT, Tersbøl B, Lange T, Makyao N, et al. Effectiveness of health care workers and peer engagement in promoting access to health services among population at higher risk for HIV in Tanzania (KPHEALTH): study protocol for a quasi experimental trial. BMC Health Services Research. 2019;19(1):801.

21. Comiskey A, Parent MC, Tebbe EA. An inhospitable world: Exploring a model of objectification theory with trans women. Psychology of Women Quarterly. 2020;44(1):105-16.

22. UNAIDS. UNAIDS Submission to the Office of the High Commissioner for Human Rights pursuant to Human Rights Council resolution 32/31 on civil society space: Input into the report on "Civil society space in multilateral institutions" 2017 [cited 2021 27-08]. Available from: https://www.ohchr.org/Documents/AboutUs/CivilSociety/Procedures/UN/JointUnitedNationsProgrammeHIV_AIDS.pdf.

23. UN Women. Global Database on Violence against Women: UN Women; 2016 [Available from: https://evaw-globaldatabase.unwomen.org/fr/countries/africa/uganda/na/gbv-shelters.

24. Rule A, Izquierdo J, Piccioli A. Reducing GBV risks through better shelter programme design. Forced Migration Review. 2017(55).

25. Maripfonde TL, Mavondo GA, Chamisa JA. Community Perceptions on the Services Offered to Gender-Based Violence Survivors in Safe Shelter of Buhera District, Zimbabwe. Asian Journal of Research in Nursing and Health. 2020:79-96.

26. Scott M. Accountability for state failures to prevent sexual assault in evacuation centres and temporary shelters: a human rights-based approach. Climate Hazards, Disasters, and Gender Ramifications: Routledge; 2019. p. 249-73.

27. Ogbe E, Jbour A, Rahbari L, Unnithan M, Degomme O. The potential role of network-oriented interventions for survivors of sexual and gender-based violence among asylum seekers in Belgium. BMC Public Health. 2021;21(1):25.

28. Nemoto T, Bödeker B, Iwamoto M. Social support, exposure to violence and transphobia, and correlates of depression among male-to-female transgender women with a history of sex work. American Journal of Public Health. 2011;101(10):1980-8.

29. Lanham M, Ridgeway K, Dayton R, Castillo BM, Brennan C, Davis DA, et al. "We're Going to Leave You for Last, Because of How You Are": Transgender Women's Experiences of Gender-Based Violence in Healthcare, Education, and Police Encounters in Latin America and the Caribbean. Violence and Gender. 2018;6(1):37-46.

30. Miles-Johnson T. Policing transgender people: Discretionary police power and the ineffectual aspirations of one Australian police initiative. SAGE Open. 2015;5(2):2158244015581189.

31. King R, Nanteza J, Sebyala Z, Bbaale J, Sande E, Poteat T, et al. HIV and transgender women in Kampala, UgandaDouble Jeopardy. Culture, health \& sexuality. 2019;21(6):727-40.

32. Minor Peters M. 'They wrote "gay" on her file': transgender Ugandans in HIV prevention and treatment. Culture, health \& sexuality. 2016;18(1):84-98.

33. Musyoki H, Bhattacharjee P, Sabin K, Ngoksin E, Wheeler T, Dallabetta G. A decade and beyond: learnings from HIV programming with underserved and marginalized key populations in Kenya. Journal of the International AIDS Society. 2021;24:e25729.

34. Samudzi Z, Mannell J. Cisgender male and transgender female sex workers in South Africa: gender variant identities and narratives of exclusion. Culture, health \& sexuality. 2016;18(1):1-14. 
35. Scheibe A, Howell S, Müller A, Katumba M, Langen B, Artz L, et al. Finding solid ground: law enforcement, key populations and their health and rights in South Africa. Journal of the International AIDS Society. 2016;19:20872.

36. Uganda Penal Code Act. 2020.

37. Kimani M, Sanders EJ, Chirro O, Mukuria N, Mahmoud S, Rinke de Wit TF, et al. Pre-exposure prophylaxis for transgender women and men who have sex with men: qualitative insights from healthcare providers, community organization-based leadership and end users in coastal Kenya. International Health. 2021.

38. Ssekamatte T, Isunju JB, Naume M, Buregyeya E, Mugambe RK, Wanyenze RK, et al. Barriers to access and utilisation of HIV/STIs prevention and care services among trans-women sex workers in the greater Kampala metropolitan area, Uganda. BMC Infectious Diseases. 2020;20(1):932.

39. Rodella Sapia MD, Wangmo T, Dagron S, Elger BS. Understanding access to professional healthcare among asylum seekers facing gender-based violence: a qualitative study from a stakeholder perspective. BMC International Health and Human Rights. 2020;20(1):25.

40. Sundus A, Shahzad S, Younas A. Ethical and culturally competent care of transgender patients: A scoping review. Nursing Ethics. 2021:0969733020988307.

41. Ssekamatte T, Isunju JB, Naume M, Buregyeya E, Mugambe RK, Wanyenze RK, et al. Barriers to access and utilisation of HIV/STIs prevention and care services among trans-women sex workers in the greater Kampala metropolitan area, Uganda. BMC infectious diseases. 2020;20(1):932. 